\title{
Sistem Informasi Manajemen Pengarsipan Surat Masuk Dan Surat Keluar (Studi Kasus : Ma Darul Ihya Bogor)
}

\author{
Sintia Mahmudah ${ }^{1}$, Lisda Widiastuti ${ }^{1}$, Siti Ernawati $^{2 *}$ \\ ${ }^{1}$ Fakultas Teknologi Informasi, Sistem Informasi Akuntansi PSDKU Bogor, Universitas Bina Sarana Informatika, Jakarta, \\ Indonesia \\ ${ }^{2}$ Sistem Informasi, STMIK Nusa Mandiri, Jakarta, Indonesia \\ Email: ${ }^{1}$ sintiamahmudah@ gmail.com, ${ }^{1}$ lisda.ltt@bsi.ac.id, ${ }^{2 *}$ siti.ste@ nusamandiri.ac.id
}

\begin{abstract}
Abstrak
Pada MA Darul Ihya Bogor surat menyurat merupakan sarana yang penting dalam berkomunikasi. Salah satu permasalahan dalam pengelolaan surat di MA Darul Ihya Bogor ketidakefisienan pengarsipan data surat yang masih menggunakan sistem manual. Dengan banyaknya jumlah surat masuk dan surat keluar setiap harinya membuat tumpukan surat yang ada didalam arsip sehingga pencarian menjadi tidak efisien dikarnakan tidak semua arsip tersusun dengan baik. Salah satu upaya untuk mengatasi hal tersebut adalah dengan membuat sistem informasi manajemen surat masuk dan keluar. Metode penelitian yang digunakan dalam penelitian ini adalah metode System Development Life Cycle (SDLC) dengan model Waterfall. Model air terjun (waterfall) sering juga disebut model sekuensial linier (sequential liniear). Hasil dari penelitian ini adalah membuat sistem informasi manajemen berbasis website ini dapat mempermudah bagian tata usaha dalam proses penginputan data surat masuk dan surat keluar, pencarian data surat masuk dan keluar, pembuatan laporan data surat masuk dan keluar sehingga menghasilkan informasi yang dibutuhkan dengan cepat dan akurat.
\end{abstract}

Kata Kunci: Arsip, Surat Masuk, Surat Keluar, SDLC, Model Air Terjun

\begin{abstract}
At MA Darul Ihya Bogor correspondence is an important means of communication. One of the problems in managing letters at the MA Darul Ihya Bogor is the inefficient filing of mail data that still uses a manual system. With the number of incoming letters and outgoing letters each meeting makes a letter that is in the archive so that the search becomes inefficient because not all files are arranged properly. One effort to overcome this problem is to create an in and outgoing mail management information system. The research method used in this study is the method of Lifecycle Development (SDLC) with the Waterfall model. The waterfall model (waterfall) is often also called a linear sequential (linear sequential) model. The results of this study are to make this site-based management information system can facilitate business administration in the process of inputting incoming and outgoing mail data, searching for incoming and outgoing mail data, making reports of incoming and outgoing mail data producing the required information quickly and accurately.
\end{abstract}

Keywords: Archives, Inboxes, Outgoing Letters, SDLC, Waterfalls

\section{PENDAHULUAN}

Berdasarkan Undang-Undang Nomor 43 Tahun 2009 Tentang Kearsipan yang menyatakan bahwa arsip adalah rekaman kegiatan atau peristiwa dalam berbagai bentuk dan media sesuai dengan perkembangan teknologi informasi dan komunikasi yang dibuat dan diterima oleh lembaga negara, pemerintahan daerah, lembaga pendidikan, perusahaan, organisasi politik, organisasi kemasyarakatan, dan perseorangan dalam pelaksanaan kehidupan bermasyarakat, berbangsa, dan bernegara[1].

Setiap kegiatan atau pekerjaan didalam suatu instansi atau organisasi diharuskan melakukan pengarsipan data dan pengelolaan data menjadi informasi yang bermanfaat bagi instansi atau organisasi tersebut, baik digunakan sebagai bukti atau legalitas maupun sebagai bahan dalam proses pengambilan suatu keputusan.

Salah satu permasalahan yang timbul dalam studi kasus pada MA Darul Ihya Bogor adalah ketidakefisienan dalam manajemen pengarsipan data surat, baik surat masuk maupun surat keluar yang masih menggunakan sistem manual. Jika sewaktu-waktu surat tersebut dibutuhkan, bagian Tata Usaha akan mencari dengan membuka tumpukan surat yang ada didalam arsip sehingga kesulitan saat melakukan pencarian surat karena tidak semua arsip tersusun dengan baik, maka hal ini menyebabkan proses pencarian surat menjadi lambat. Permasalahan lain yang timbul, Saat penyimpanan surat tersebut tidak sesuai dengan jenis surat atau kategori surat, maka hal ini menyebabkan proses pencarian surat menjadi lambat, bahkan tak jarang surat yang dimaksud tidak ditemukan padahal sebenarnya surat itu ada[2].

Berdasarkan uraian latar belakang masalah tersebut perlu dibuatnya suatu sistem untuk memanajemen surat masuk dan surat keluar agar dapat memudahkan bagian Tata Usaha dalam pengarsipan sehingga menghasilkan informasi yang dibutuhkan dengan cepat dan akurat.

Penyimpanan arsip-arsip tersebut akan berupa file atau softcopy dengan disertai kode-kode tertentu sehingga memungkinkan kemudahan dan kenyamanan dalam hal pencarian dan tidak rusak dimakan waktu[3].

Penggunaan sistem informasi manajemen yang terkomputerisasi dirasakan akan sangat bermanfaat bagi instansi pemerintahan maupun swasta. Terutama pada bagian pengarsipan dikarenakan pengarsipan merupakan ujung tombak dari sebuah informasi yang sangat berkualitas[4]. 


\section{METODE PENELITIAN}

\subsection{Pengumpulan Data}

Dalam rangka pengumpulan data untuk penelitian ini ada tiga macam metode yaitu:

a. Interview / Wawancara

Wawancara yang dilakukan ini bertujuan untuk mendapatkan informasi secara lengkap, dengan cara melakukan metode tanya jawab secara langsung kepada Bapak Kepala Sekolah MA Darul Ihya Bogor.

b. Pengamatan ( Observasi )

Penulis melakukan pengamatan secara langsung aktivitas pengarsipan di MA Darul Ihya Bogor. Metode ini akan memberikan gambaran awal tentang skema pengelolaan surat yang saat ini digunakan di MA Darul Ihya Bogor.

c. Studi Pusaka

Penelitian ini bertujuan untuk mengumpulkan data dan mempelajari buku-buku, jurnal serta mencari informasi yang diperlukan.

\subsection{Model Waterfall}

Metode yang digunakan pada penelitian ini menggunakan model waterfall[5] yaitu:

a. Analisis Kebutuhan

Pada tahap ini penulis menjelaskan kebutuhan awal dalam sistem yang sedang berjalan. Pengguna membutuhkan aplikasi yang dapat membantu proses pengelolaan pengarsipan surat masuk dan surat keluar serta pembuatan laporan.

b. Desain

Desain sistem adalah merancang sistem baru yang terkomputerisasi, Pada tahap ini desain pembuatan program sistem menggunakan rancangan yang meliputi usecase diagram, activity diagram, class diagram, ERD, LRS, sequence diagram.

c. Pembuatan kode program

Pengkodean merupakan upaya dalam pengimplementasian desain menjadi perangkat lunak. Dalam tahapan ini, penulis melakukan pembuatan kode program dengan menggunakan java application dan MySQL dalam pembuatan database.

d. Pengujian

Pengujian merupakan upaya dalam menelusuri lebih lanjut terhadap perangkat lunak yang telah dibuat untuk mendapatkan informasi mengenai kualitas perangkat lunak yang sedang diuji. Dalam tahapan ini, metode yang digunakan untuk pengujian yaitu metode black box testing penulis melakukan pengujian yang berfokus pada perangkat lunak dari segi logik dan fungsional.

e. Pendukung (support) atau pemeliharaan (maintenance)

Pendukung merupakan kegiatan yang dilakukan dalam perawatan dan pengubahan atau pengembangan dari perangkat lunak yang telah dibuat dan tidak terdeteksi saat tahapan pengujian. Dalam tahapan ini, penulis melakukan perawatan terhadap perangkat lunak secara berkala, pengubahan atau pengembangan dilakukan apabila terjadi kesalahan di dalam perangkat lunak yang tidak terdeteksi pada saat pengujian.

Namun, penulis hanya menggunakan beberapa tahapan dalam metode waterfall yang terdiri dari perencanaan, analisis dan perancangan saja dikarenakan penulis melakukan fokus pada perancangan sistem.

\section{ANALISA DAN PEMBAHASAN}

Berikut ini akan dijelaskan perancangan sistem pengarsipan surat masuk dan surat keluar pada sekolah MA Darul Ihya Bogor, dalam sistem ini sebenarnya tidak mengalami perubahan dari sistem berjalan, hanya saja penambahan pengguna komputer lebih dioptimalkan.

\subsection{Analisis Kebutuhan Sistem}

Analisis kebutuhan sistem menguraikan kebutuhan sistem agar dapat memberikan gambaran tentang sistem yang diamati yang saat ini sedang berjalan. Data yang dijadikan bahan uji dan analisis didapatkan dari hasil analisis sistem lama untuk pembangunan dan penerapan sebuah aplikasi sistem yang diusulkan.

\subsection{Analisa Kebutuhan Pengguna}

Dalam aplikasi pengarsipan ini terdapat dua pengguna yang dapat mengakses sistem pengarsipan surat masuk dan surat keluar yaitu bagian tata usaha dan kepala sekolah, kedua pengguna tersebut memiliki karakteristik interaksi dengan sistem yang berbeda-beda dan memiliki kebutuhan informasi yang berbeda-beda seperti berikut:

a. Skenario kebutuhan bagian tata usaha

1. Menginput surat masuk

2. Menginput surat keluar

3. Menginput buku ekspedisi surat keluar 
JURNAL MEDIA INFORMATIKA BUDIDARMA, Vol 3, No 3, Juli 2019

ISSN 2614-5278 (media cetak)

ISSN 2548-8368 (media online)

Hal 225-231 | DOI: 10.30865/mib.v3i3.1215

b. Skenario bagian kepala sekolah

Kepala sekolah dapat melihat laporan surat

\subsection{Rancangan Basis Data}

Berikut uraian penelitian mengenai rancangan basis data:

a. Use Case Diagram

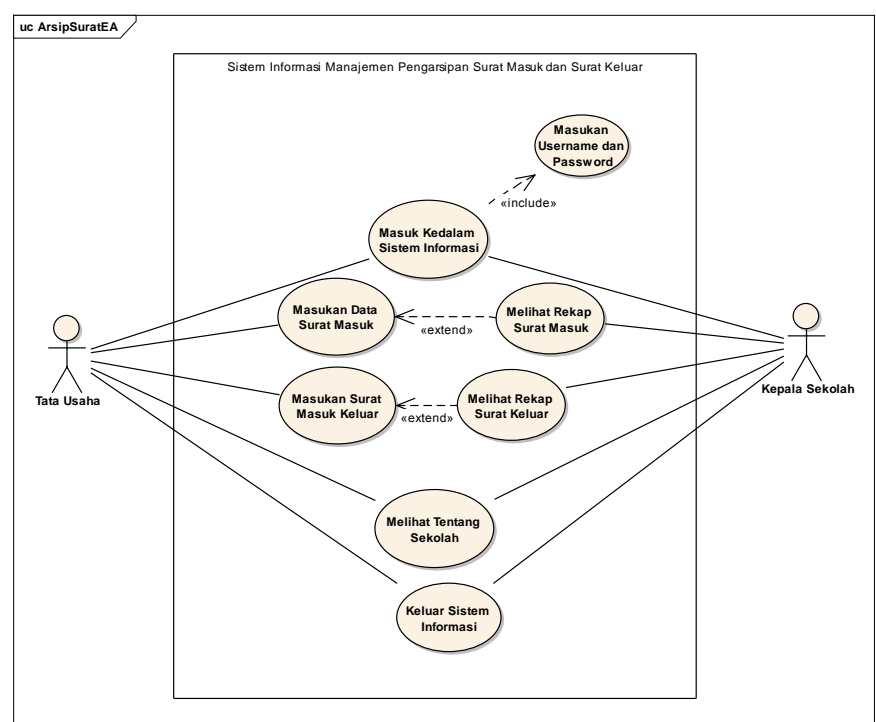

Gambar 1. Use Case Utama

b. Activity Diagram

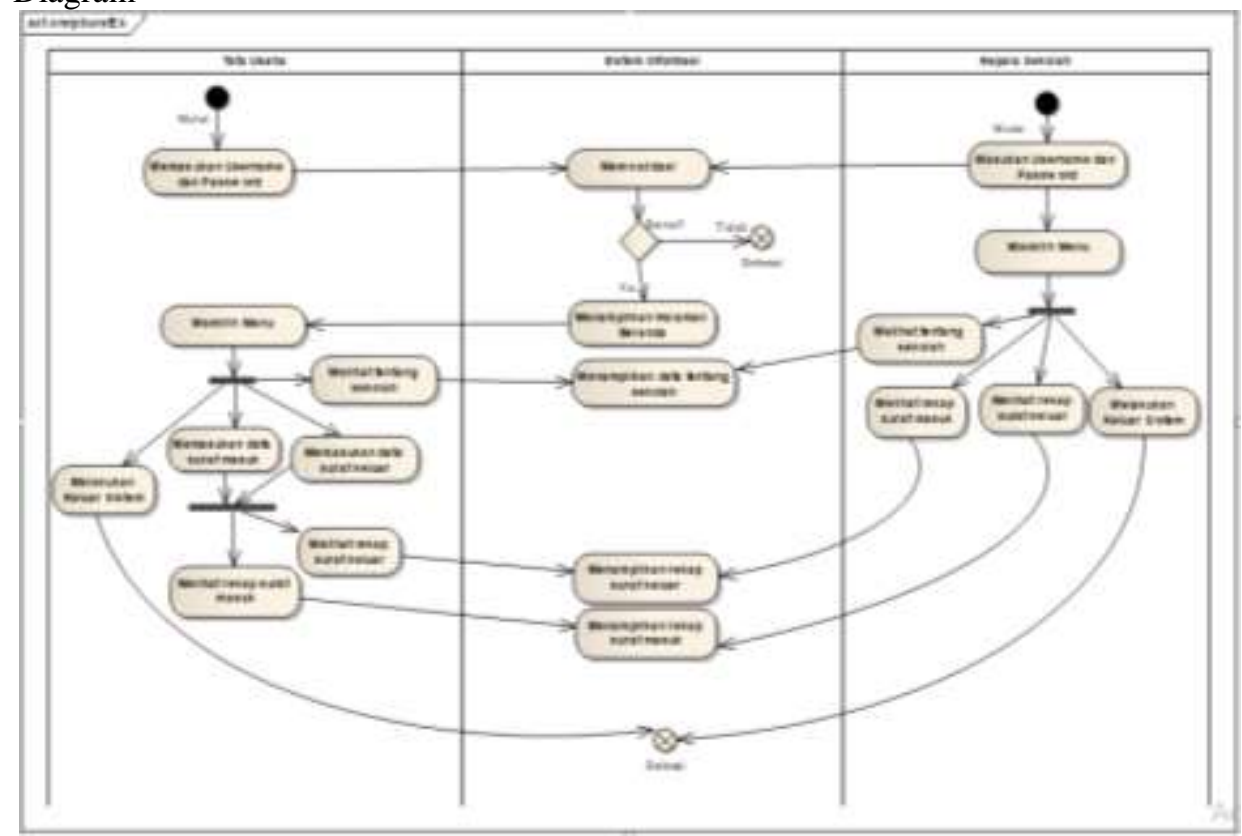

Gambar 2. Activity Diagram

c. Dokumen Sistem Usulan

Adapun rancangan dokumen keluaran sistem usulan adalah:

1. Nama dokumen : laporan surat masuk

Fungsi

Sumber

Tujuan

: sebagai laporan surat masuk

: tata usaha

Media

: kepala sekolah

Jumlah

: cetakan komputer/softcopy file

Frekuensi

: 1 kertas

2. Nama dokumen

Fungsi

: setiap akhir periode

Sumber

: laporan surat keluar

: sebagai laporan surat keluar

: tata usaha 
JURNAL MEDIA INFORMATIKA BUDIDARMA, Vol 3, No 3, Juli 2019

ISSN 2614-5278 (media cetak)

ISSN 2548-8368 (media online)

Hal 225-231 | DOI: 10.30865/mib.v3i3.1215

Tujuan

Media

Jumlah

Frekuensi

3. Nama dokumen

Fungsi

Sumber

Tujuan

Media

Jumlah

Frekuensi
: kepala sekolah

: cetakan kompter/softcopy file

: 1 kertas

: setiap akhir periode

: laporan ekspedisi surat keluar

: sebagai laporan surat masuk

: tata usaha

: kepala sekolah

: cetakan komputer/softcopy file

: 1 kertas

: setiap akhir periode

d. Entity Relationship Diagram (ERD)

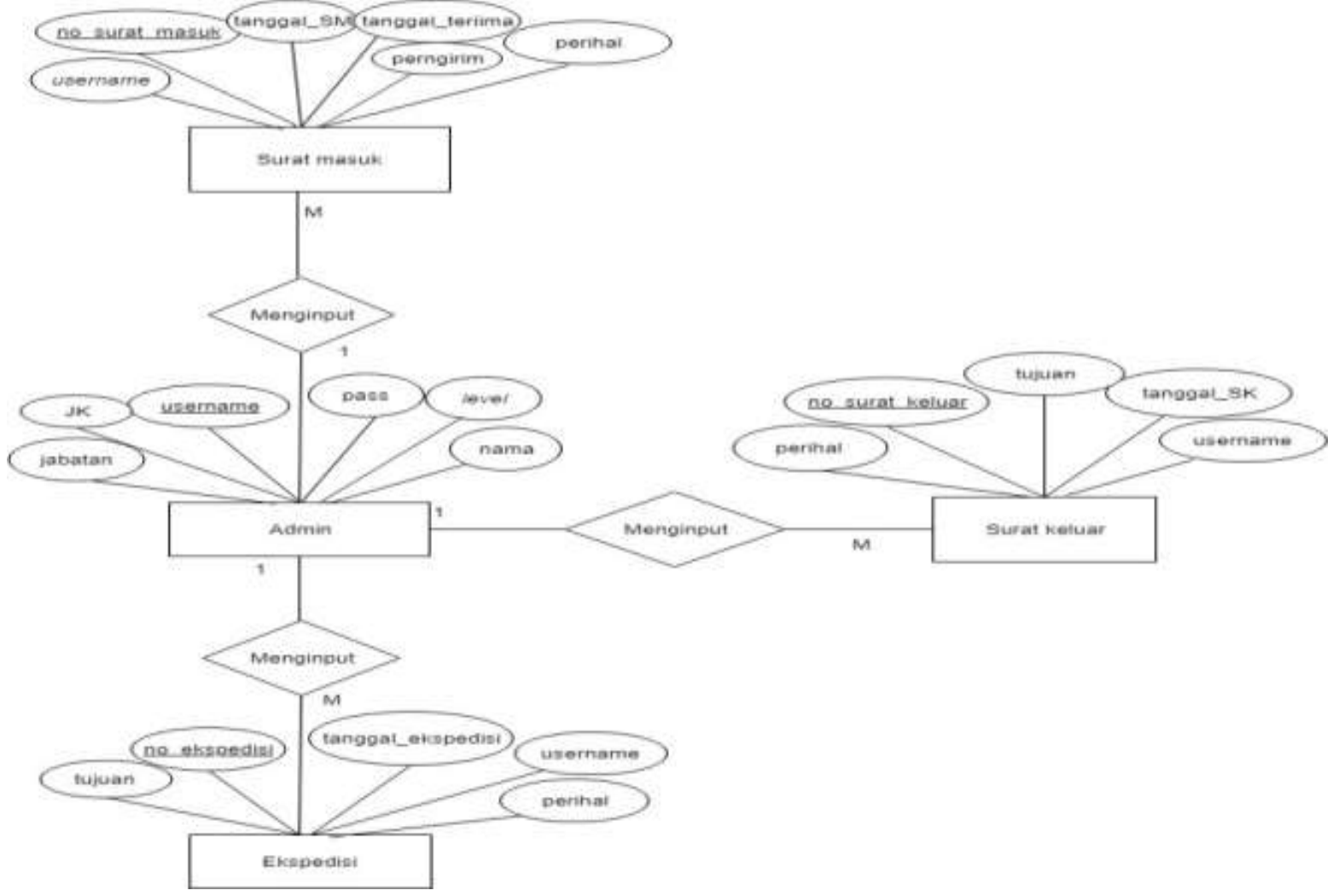

Gambar 3. Entity Relationship Diagram

e. Logical Record Structure (LRS)

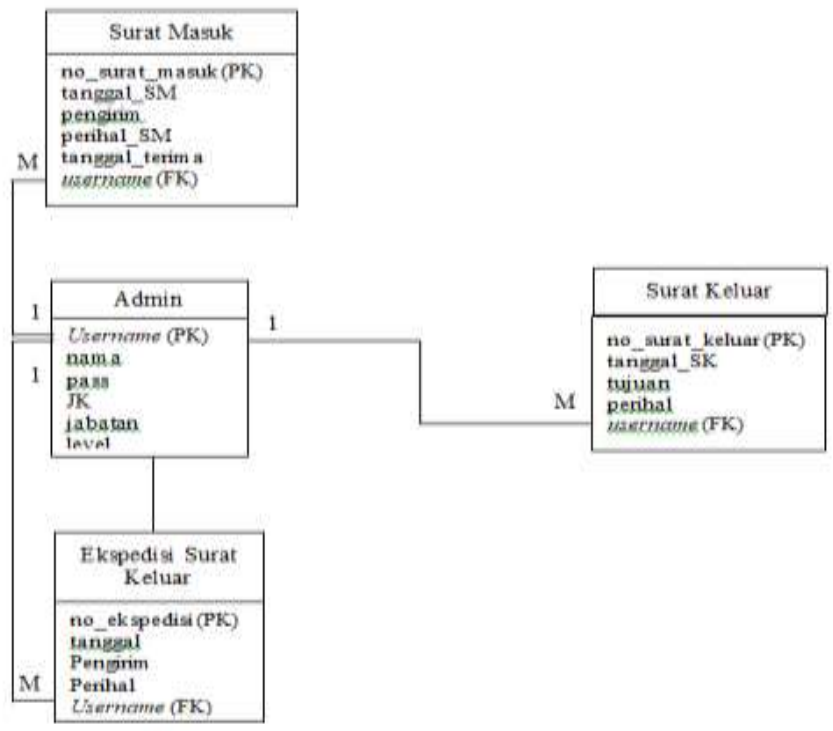

Gambar 4. Logical Record Structure 
JURNAL MEDIA INFORMATIKA BUDIDARMA, Vol 3, No 3, Juli 2019

ISSN 2614-5278 (media cetak)

ISSN 2548-8368 (media online)

Hal 225-231 | DOI: 10.30865/mib.v3i3.1215

f. Class Diagram

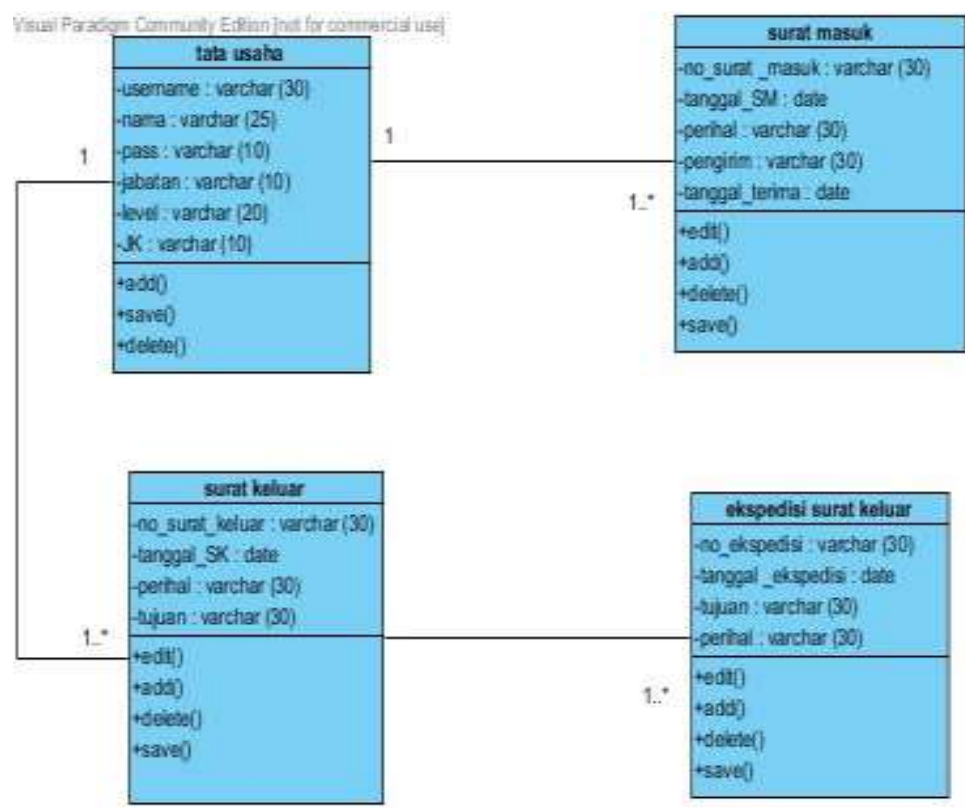

Gambar 5. Class Diagram

g. Sequence Diagram

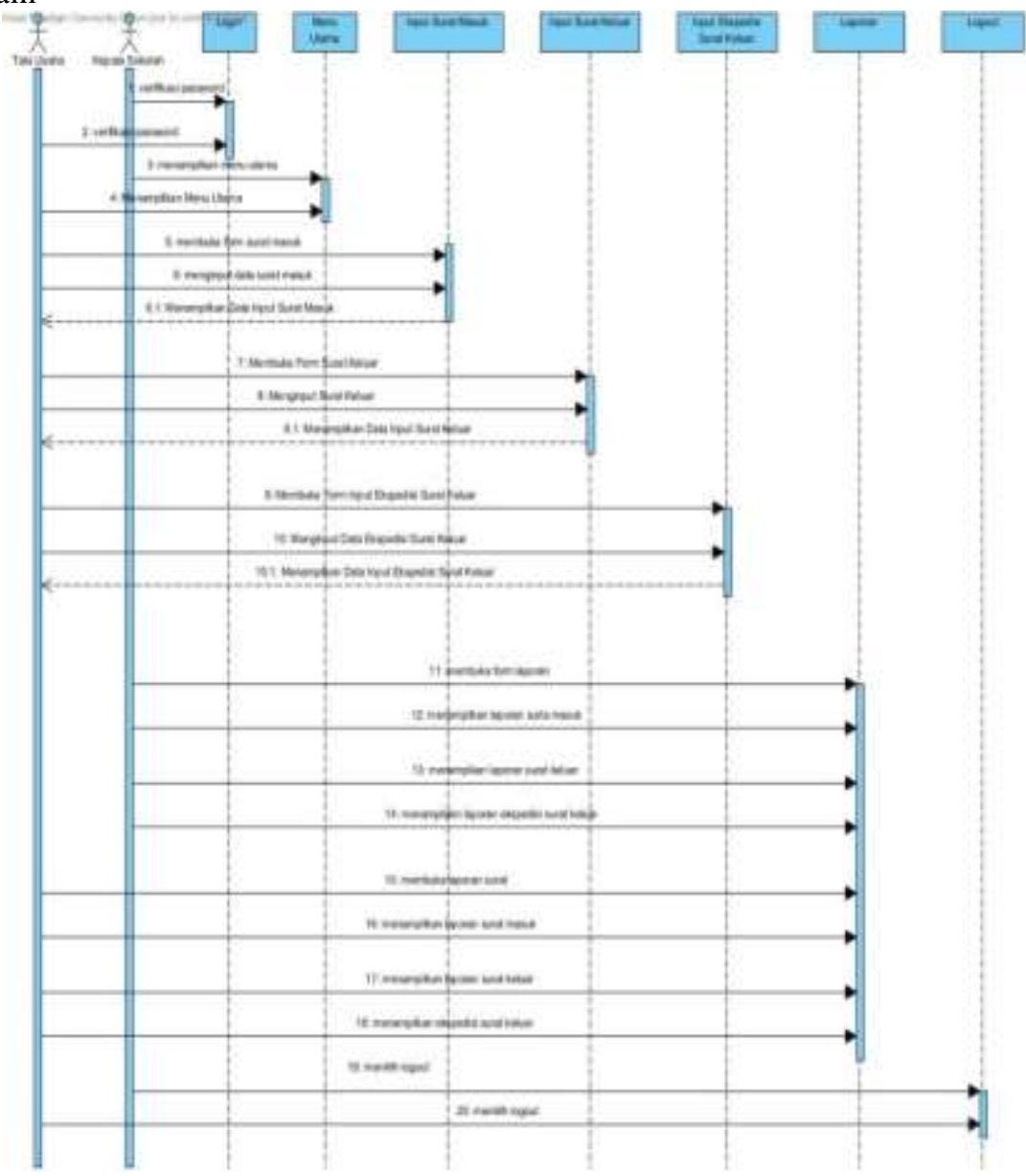

Gambar 6. Sequence Diagram Pengarsipan

\section{IMPLEMENTASI}

Adapun tahap pengujian terhadap sistem informasi manajemen pengarsipan surat masuk dan surat keluar pada MA Darul Ihya Bogor:

a. Halaman Masuk Sistem Informasi 


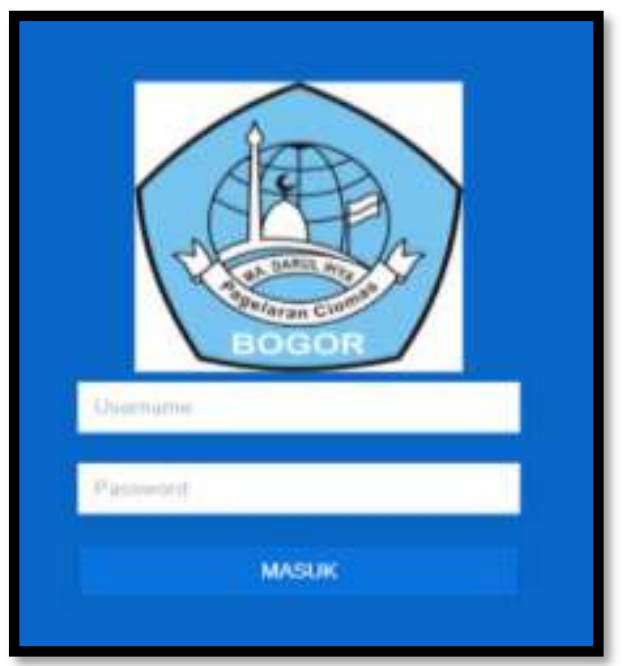

Gambar 7. Halaman Masuk Sistem Informasi

b. Halaman Beranda

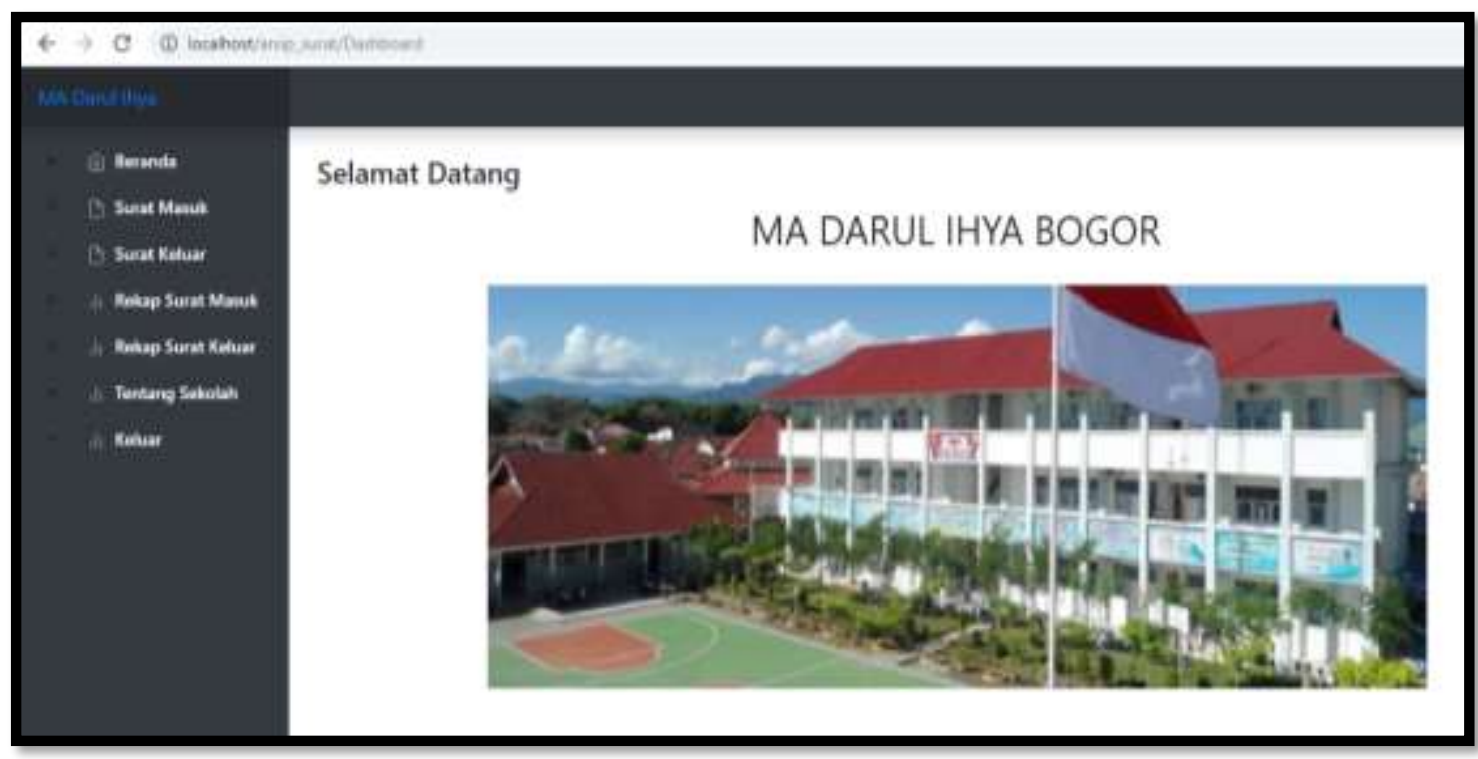

Gambar 8. Halaman Beranda

c. Halaman Surat Masuk

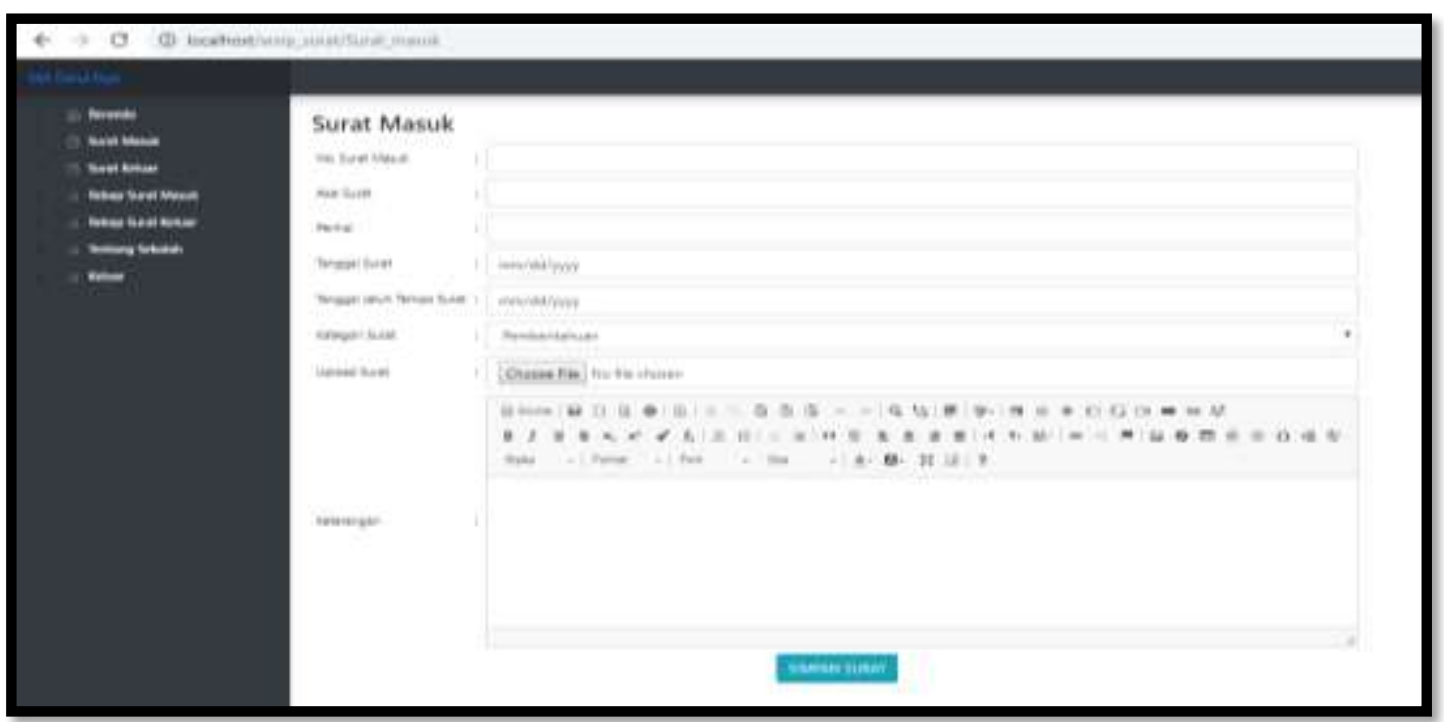

Gambar 9. Halaman Surat Masuk

Sintia Mahmudah | http://ejurnal.stmik-budidarma.ac.id/index.php/mib | Page 230 
d. Halaman Surat Keluar

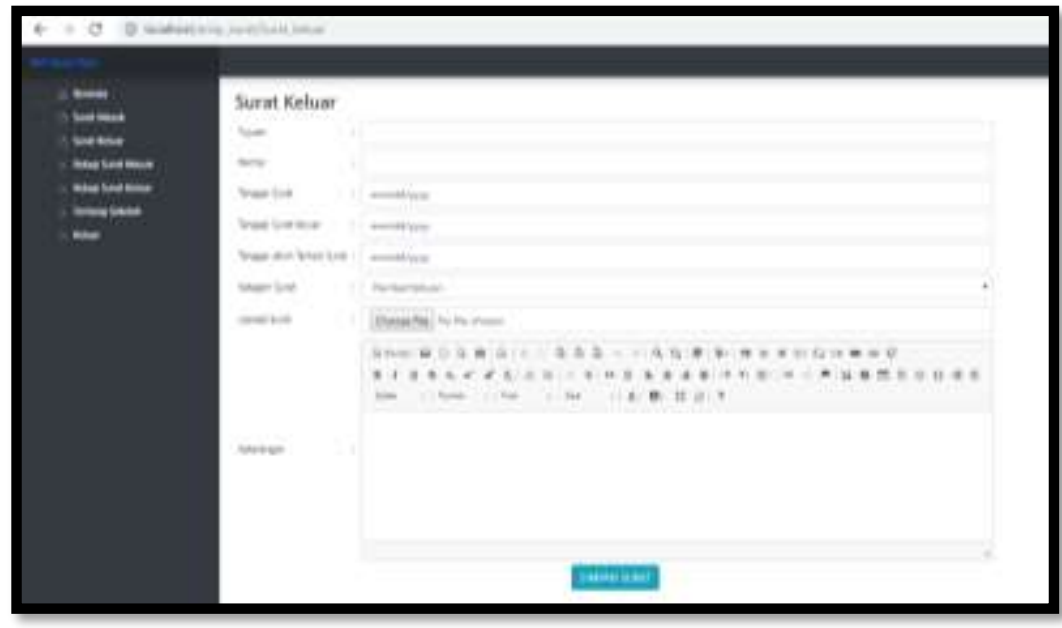

Gambar 10. Halaman Surat Keluar

e. Halaman Rekap Surat Masuk

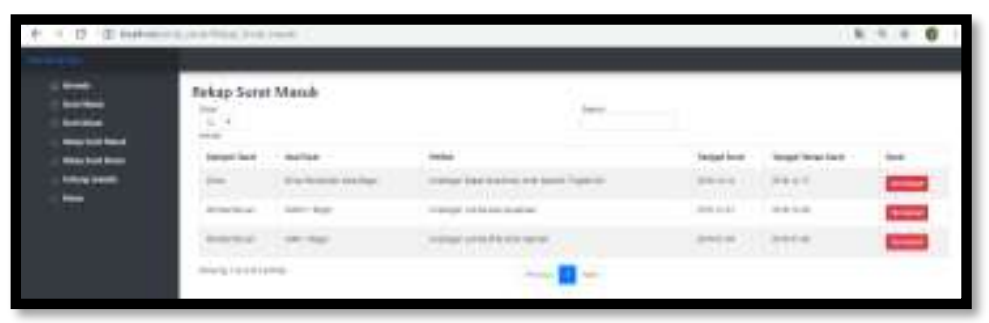

Gambar 11. Halaman Rekap Surat Masuk

f. Halaman Rekap Surat Keluar

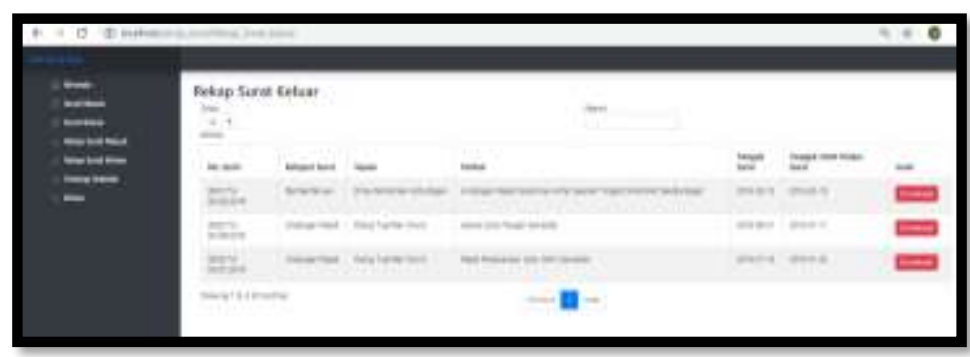

Gambar 11. Halaman Rekap Surat Keluar

\section{KESIMPULAN}

Pada dasarnya penulis tidak merubah sistem berjalan yang sudah ada pada MA Darul Ihya Bogor melainkan hanya pencatatan dan penyimpanan saja yang terkomputesisasi. Dari hasil penelitian yang telah penulis lakukan, dapat diambil kesimpulan bahwa Sistem pengarsipan surat masuk dan surat keluar berbasis website dapat mempermudah memanajemen surat sehingga dapat lebih efektif dan efisien dalam penyimpanannya serta dapat mempermudah dalam pembuatan laporan sesuai dengan kebutuhan.

\section{REFERENCES}

[1] Pemerintah Indonesia. 2009. Undang-Undang No. 43 Tahun 2009 tentang Kerasipan. Lembaran Negara Republik Indonesia tahun 2009 Nomor 152. Sekretariat Negara RI. Jakarta.

[2] Srirahayu, 2016, Sistem Informasi Pendataan Surat Masuk dan Surat Keluar Pada Smk Negeri 5 Tanggerang. Eksplora Informatika, 5, 138-146.

[3] Masykur, Fauzan \& Ibnu Makruf, P. 2015, Sistem Administrasi Pengelolaan Arsip Surat masuk dan Surat keluar Berbasis Web. Indonesia Journal on Networking and Security, 1-7.

[4] Meilinda, E, 2016, Perancangan Aplikasi Kearsipan Surat Menyurat Pada Badan Pemerintahan. Jurnal Khatulistiwa Informatika, Iv(2), $144-152$.

[5] Sukamto \& Shalahuddin, 2014, Rekayasa Perangkat Lunak Terstruktur dan Berorientasi Objek. Bandung: Informatika. 